\title{
Efficiency Analysis of Switched Reluctance Generator According to Current Shape under Rated Speed
}

\author{
Siyang Yu***, Dong-Hee Lee** and Jin-Woo Ahn **
}

\begin{abstract}
This paper introduces the high efficiency operation of switched reluctance generator (SRG). The proposed SRG operates under the rated speed. The high efficiency can be obtained by the optimal current shape which can make the total losses minimum. For this purpose, theoretical analysis of the copper and core loss is done. In addition, a modified angle position control (MAPC) method which can get the optimal current shape over wide speed condition is presented. In order to verity the theory, the experimental platform is set up. The feasibility of the theory is verified by the simulation and experimental results. The proposed method is simple, reliable and easy to achieve.
\end{abstract}

Keywords: Switched reluctance generator, Current shape, High efficiency

\section{Introduction}

There are a lot of advantages of the switched reluctance generator (SRG). The rotor construction is very simple, because it consists of only laminated steel. The stator part consists of concentrated phase windings mounted around salient poles [1]. This is good in a commercial sense, as manufacturing cost is low [2]. Besides, the absence of windings and permanent magnets on the rotor encourage high-speed and high temperature operation of the SRG [3]. Furthermore, each phase of SRG is electrically and magnetically independent from others, and it confirms improved system reliability $[4,5]$. The merits of using SRG have been proved for some applications like starter/generator for gas turbine of aircrafts [6], windmill generator [7] and as an alternator for automotive applications [8]. The objective of SRG control is normally to track the output power and keep the DC-link voltage at a desired value with high efficiency, low torque ripple, and low acoustic noise. These control objectives can be optimized by appropriately adjusting the turn on/off angles and other parameters of SRG.

At present, there is little relevant literature about improving the system efficiency of SRG, especially the SRG is operated at low and medium speed condition. In [9], for whole operating speeds, all possible turn on and conduction angles have been simulated to get the desired

\footnotetext{
* School of Electrical Engineering, Shenyang University of

Technology, China, 110870 (yusiyangnuli@163.com)

** Department of Mechatronics Engineering, Kyungsung University, Busan 608-736, Korea (leedh@ks.ac.kr , jwahn@ks.ac.kr)
}

power factor. In other words, the copper losses have been minimized and the efficiency has been improved. In [2], the control of excitation of SRG for maximum efficiency at single pulse mode of operation has been presented. Turn on and turn off angles are defined as control variables, turn on angle is set based on the output power and turn off angle is selected to achieve optimal efficiency at each power level and speed. In [10], a new performance criteria as productivity of generator is described, in this method, instead of two phase commutation steps, which are on and off in single pulse mode, a freewheeling step is added. During this step, the phase is short circuited and the current increases due to back-emf voltage. This method produces more power than the conventional method, for the same conduction period and it reduces current ripple on DC-link bus. Current chopping control and single pulse control are adopted respectively as inner loop to hold on DC-link voltage in [11] and [12]. Moreover, optimal turn on/off angle is chosen by analysis of the system efficiency and torque ripple in [11]. While, in [12], the optimal turn on/off angle is calculated by a ratio of two fluxes. One is the flux at the point where entire-overlapped stator and rotor poles start to detach, and another is the max flux. In [13], the optimal turn on/off angle which corresponding the high system efficiency is selected by measuring and analyzing the system losses of different reference powers and speeds. The control system in this paper is constituted by PI power controller and two-level current hysteresis controller. Based on measured magnetization curve, optimal turn on/off angle can be obtained by analyzing output power and system efficiency under a series of different on/off angle in [14].

In this paper, high efficiency operation of SRG is the 
main objective. The effect of phase current waveform on the system efficiency during the SRG system power generation stage is analyzed. The optimal current waveform which can make the system operate with high efficiency is obtained by the theoretical analysis and simulation of the copper loss and core loss. A modified angle position control (MAPC) method which can get the optimal current shape is presented. The feasibility of the theory are verified by the experiment.

\section{Analyze of SRG operation}

\subsection{Operation principle}

There are many configurations for SRG; Fig. 1 illustrates a basic structure of a four phase SRG used in this paper.

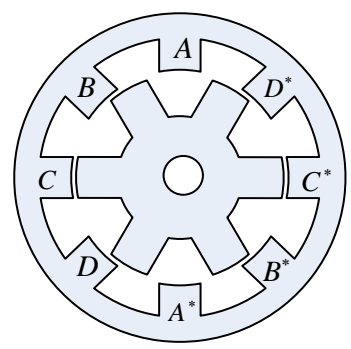

Fig. 1. Cross section of a four phase SRG

Voltage equation for each phase of SRG is given by

$$
u_{p h}=R_{p h} i_{p h}+L\left(i_{p h}, \theta\right) \frac{d i_{p h}}{d t}+e_{p h}
$$

where, subscript $p h$ is one of these phases, $R_{p h}$ is the phase resistance, the phase inductance $L$ is the function of the rotor position $\theta$ and the phase current $i_{p h}$, and $e_{p h}=i_{p h} \omega \partial L\left(i_{p h}, \theta\right) / \partial \theta$ is back-emf.

A switched reluctance machine operates in generating mode, if each phase is excited after aligned position, where the phase inductance decreases, $\partial L / \partial \theta<0$. From (1), it can be known that, the behavior of the phase current depends on the relationship between back-emf and source voltage. Since the amplitude of back-emf varies with rotor speed, the current waveform depends on the rotor speed.

\subsection{Calculation of main electrical losses}

The main electrical losses of a SRG are copper loss and core loss. The copper loss depends on the root-mean-square (rms) phase current and is given by

$$
P_{C u}=m I_{r m s}^{2} R_{p h}
$$

where, $m$ is the number of phase, and the $I_{r m s}$ is calculated in (3) by Fig. 3. $\theta_{r r p}=2 \pi / N_{r}$ is rotor pole pitch, and $N_{r}$ is the number of rotor poles. $\theta_{q}$ is rotor angle at which phase current extinguishes.

$$
I_{r m s}=\sqrt{\frac{1}{\theta_{r r p}} \int_{\theta_{o n}}^{\theta_{q}} i_{p h}^{2} d \theta}
$$

The core loss is proportional to the excitation magnetic motive force (mmf) and the stroke frequency. Since the flux waveform is non-sinusoidal and flux harmonic spectra differ in various parts of the magnetic circuit, core loss is not uniformly distribute in the core. In this paper, the core loss is calculated by an approximate formulae based on the actual flux waveforms for every part of SRG. In addition, Fourier analysis is used to obtain the frequency and the amplitude of the fundamental and the harmonic components. The approximate equation is shown in (4).

$$
P_{F e}=K_{h} f\left(B_{m}\right)^{2}+K_{c}\left(f B_{m}\right)^{2}
$$

where, $f$ is the stroke frequency, $K_{h}$ and $K_{c}$ is the hysteresis and eddy-current loss coefficient, respectively, and $B_{m}$ is the amplitude of flux density for sinusoidal variation.

\subsection{Calculation of system efficiency}

The system efficiency which is an important criterion for SRG performance is defined as

$$
\eta=\frac{P_{G}}{P_{M}}
$$

where, $P_{G}$ is the electrical output power of SRG, and $P_{M}$ is the mechanical input power of prime mover. The input power can be calculated by

$$
P_{M}=T_{L} \cdot \omega
$$

where, $T_{L}$ and $\omega$ is the electromagnetic torque of the prime mover and angle velocity, respectively.

From (5) and (6), it is concluded that in order to calculate the system efficiency, the measurements of $P_{\text {out }}, T_{e}$ and $\omega$ are required.

\section{Analysis of the effect of current shape on the system}

Fig. 2 is the phase currents and flux linkages with 
different current waveforms at the same output power. Under the rated speed, it can be obtained three kinds of typical current shapes by adjusting the turn-on/off angles and the voltage added on the phase during the generation stage. The three kinds of current shapes can be expressed using current slope factor CSF. The relationship between the CSF and the current shape is illustrated in Table 1. In the table, the $i_{\text {off }}$ and $i_{\text {end }}$ is the current value at rotor position $\theta_{\text {off }}$ and $\theta_{\text {end }}$, respectively. The $\theta_{\text {off }}$ and $\theta_{\text {end }}$ is the turn-off angle and the rotor position at which the stator and rotor pole corners complete overlap. From (1), it can be known that the absolute value of phase voltage is smallest as CSF is " + ", and the condition is opposite when CSF is "-". So at the same output power, the rms phase current is biggest when CSF is " + ", and as the result, the copper loss is maximum. On the contrary, the copper loss is minimum as CSF is “-”. In addition, from Fig. 2, it can be known that the peak value of flux linkage occurs on the $\theta_{\text {off }}$. So the core loss is minimum when CSF is " + ", Inversely, the peak value of flux linkage and the core loss is maximum as CSF is "-_".

Table 1. Relationship between CSF and current shape

\begin{tabular}{|c|c|c|}
\hline CSF & Current equation & Current shape \\
\hline- & $i_{\text {off }}>i_{\text {end }}$ & \\
\hline 0 & $i_{\text {off }}=i_{\text {end }}$ & \\
\hline+ & $i_{\text {off }}<i_{\text {end }}$ & $i_{\text {off }}$ \\
\hline & & \\
\hline
\end{tabular}

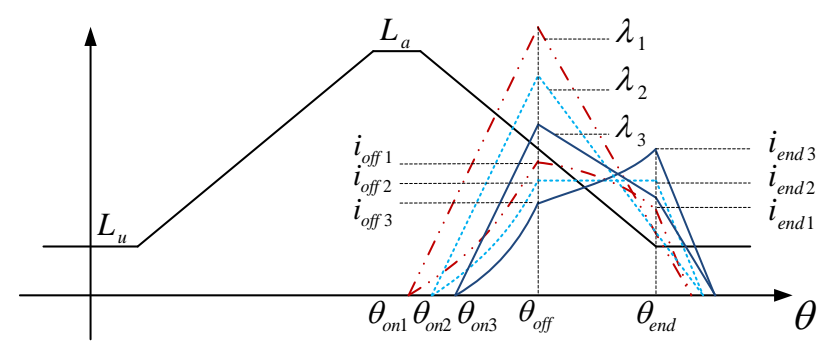

Fig. 2. Phase current and flux linkage with different current shapes at same output power

From the above it is concluded that the optimal current waveform which can make the total losses minimize is existed and the value CSF can determine the current shape.

In order to obtain the optimal current shape, the modified angle position control (MAPC) method is proposed. This method is made up of angle position control method and voltage chopping control method. So it includes the merit of these two kinds of control method.

Fig. 3 is the concept waveform of MAPC method. Where, $L_{a}$ and $L_{u}$ is the inductance value at aligned and unaligned position, respectively. $\theta_{o n}$ and $\theta_{\text {off }}$ is turn-on and turn-off rotor position, respectively. $\theta_{q}$ is the rotor position at which phase current extinguishes. $V_{d c}$ and $i_{p h}$ is the DC-link voltage and phase current, respectively. $\lambda_{p h}$ is the phase flux linkage. In addition, the $\theta_{\text {end }}$ can be calculated by (7). From (7), it can be known that, for the specific motor, value of $\theta_{\text {end }}$ is constant. According the used SRG parameters, the $\theta_{\text {end }}$ is $53.3^{\circ}$.

$$
\theta_{\text {end }}=\frac{\theta_{r r p}-\left(\beta_{S}+\beta_{r}\right)}{2}
$$

where, $\theta_{r r p}$ is the rotor pole pitch. $\beta_{s}$ and $\beta_{r}$ is stator and rotor pole arcs, respectively.

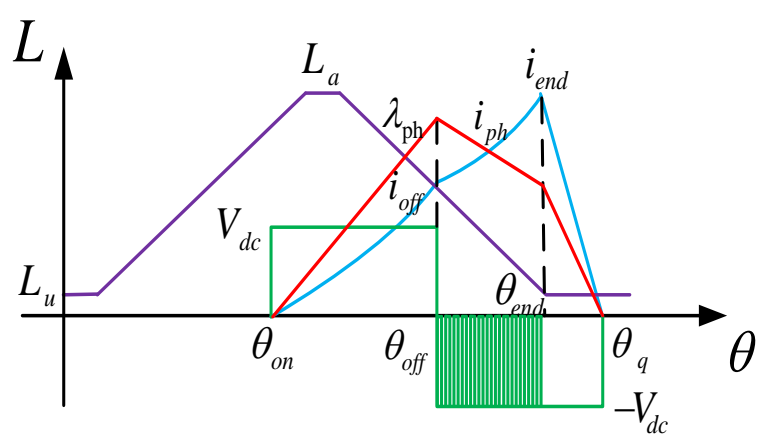

Fig. 3. Concept waveform of MAPC method

\section{Simulation and experimental results}

The control structure of the system is shown in Fig. 4, which consists of SRG, AC servo motor, power converter, angle position controller, duty calculator and position sensor. The AC servo motor serves as the prime mover in the system. The SRG as the core of the entire system plays a part that absorbs the mechanical energy from the prime mover and delivers the electrical energy to the load. In the figure, $\mathrm{P}^{*}$ and $\mathrm{P}_{\text {out }}$ is the command power and output power of SRG, respectively. $\theta_{c}$ is the dwell angle, and it is determined by the PI controller. $\theta_{o n}=\theta_{o f f}-\theta_{c}$ is turnon angle. It is worth noting that, the duty calculator is determined by the $S 1$ and CSF. The $S 1$ is the speed error single $\left(\Delta \omega=\omega^{*}-\omega\right)$. It includes two values, 0 and 1 , corresponds to the under rated speed operation and over speed operation, respectively.

The performance of the SRG drive is highly affected by 
the performance and characteristics of the converter. The power converter used in this paper is share switch type, and it can save two power switched and two diodes, so it can reduce the system cost. The structure of the converter is shown in Fig. 5. Fig. 6 takes phase A as the example to describe the operation mode of the converter. From Fig. 5 and 6 , it can be known that, the phase winding voltage depends on the state of the power switches, and the value includes $\mathrm{U}_{\mathrm{S}}, 0$, and $-\mathrm{U}_{\mathrm{S}}$.

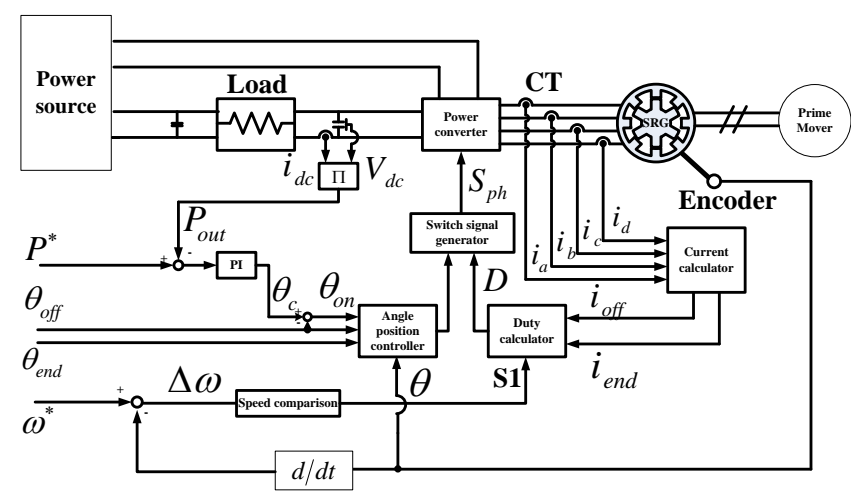

Fig. 4. Block diagram of $8 / 6$ SRG control system

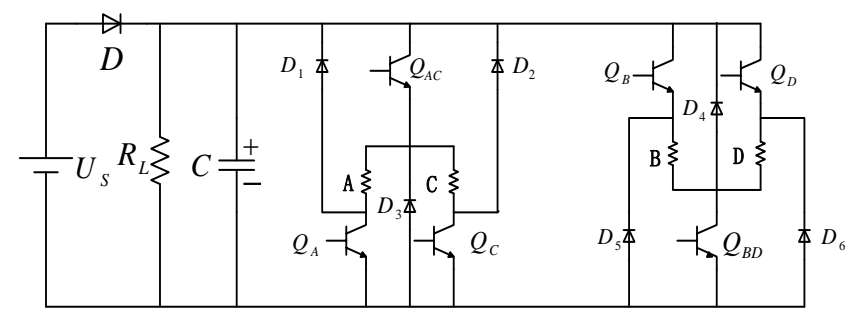

Fig. 5. Power converter of $8 / 6$ SRG

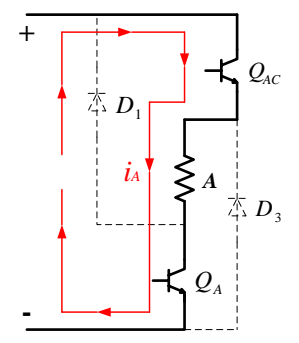

(a)

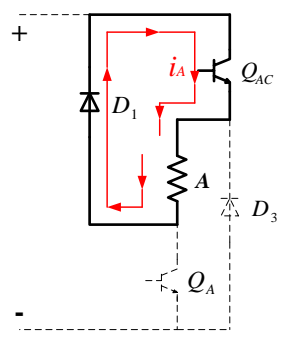

(b)

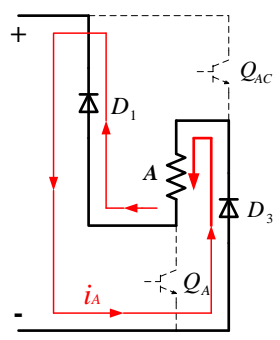

(c)
Fig. 6. Operation mode of the converter (a) magnetization mode (b) freewheeling mode (c) demagnetization mode

\subsection{Simulation results}

Fig. 7 shows the relationship between CSF and the loss. From the figure, it can be known that the copper loss will increase when the CSF value increases. However, the core loss will decrease when CSF value increases. When the CSF is " 0 ", the total loss is minimum at the same output power condition. This result matches the theoretical analysis.

Fig. 8 shows the relationship between the CSF and the efficiency. It is worth mentioning that, only the copper and core loss are considered in the simulation. The simulation condition is that source voltage is $150 \mathrm{~V}$, speed is $1000 \mathrm{rpm}$, and $\theta_{\text {off }}$ and $\theta_{\text {end }}$ is fixed at $41^{\circ}$ and $53.3^{\circ}$, respectively. From the results, it can be seen that the efficiency is maximum when CSF is " 0 ".

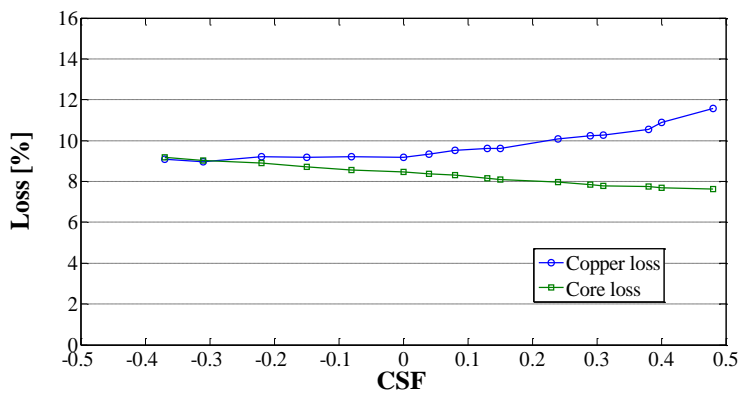

(a)

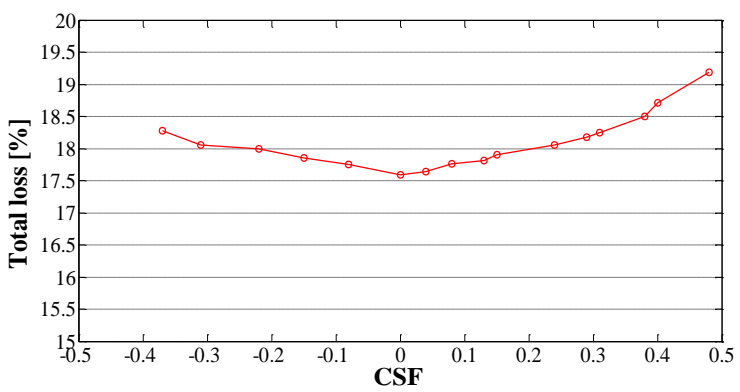

(b)

Fig. 7. Relationship between CSF and loss (a) copper and core loss (b) total loss

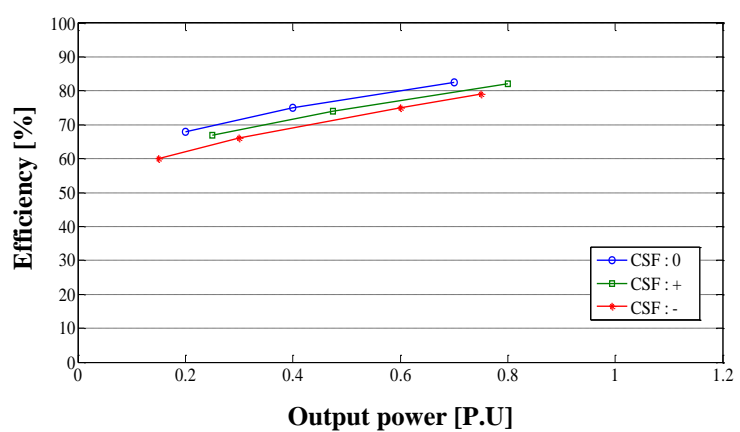

Fig. 8. Relationship between CSF and efficiency (simulation)

\subsection{Experimental results}

In order to verify the theory and simulation results, the AC servo motor and SRG system is set up. The AC servo motor is controlled by speed closed-loop method to maintain a constant speed. In experiment, the main parameters of SRG are 150V, 200W, 1500rpm, the TMS320F28335 DSP-150MHz produced by Texas Instruments is used. In addition, the precision power analyzer PPA2530 produced by Newtons4th Ltd and bipolar DC power supply BP4610 produced by NF 
corporation are used in the experiment. The experiment setup of the SRG system is shown in Fig. 9.

Fig. 10 shows the relationship between CSF and system efficiency at $1000 \mathrm{rpm}$ and $1500 \mathrm{rpm}$. In the experiment, DC-link voltage is $150 \mathrm{~V}, \theta_{\text {off }}$ and $\theta_{\text {end }}$ is fixed at $41^{\circ}$ and $53.3^{\circ}$, respectively, and the $\theta_{\text {on }}$ is a variable. In addition, the system efficiency is calculated by (5), and the $T_{e}$ and $P_{\text {out }}$ can be obtained by the AC servo motor controller and power analyzer respectively. At this time, with the decreasing of the turn-on, the output power of the SRG will increase, and the phase voltage during the generation stage which maintain the needed current waveform will increase. As shown in Fig. 10 (b), when CSF is "-", the reason why the output power less than the rated power is that if the output power continues to increase, the given current shape is not able to maintain. From Fig. 10, it can be seen obviously, the system efficiency is maximum when CSF is " 0 ". The results match the simulation results and the theoretical analysis.

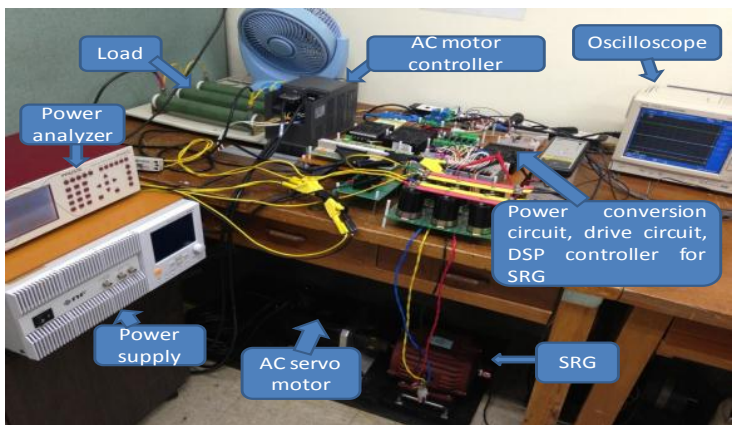

Fig. 9. Experimental platform

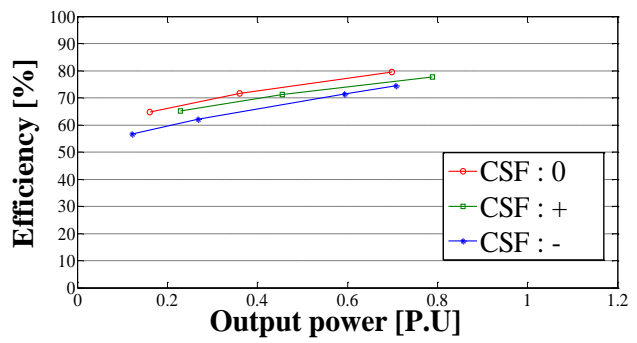

(a)

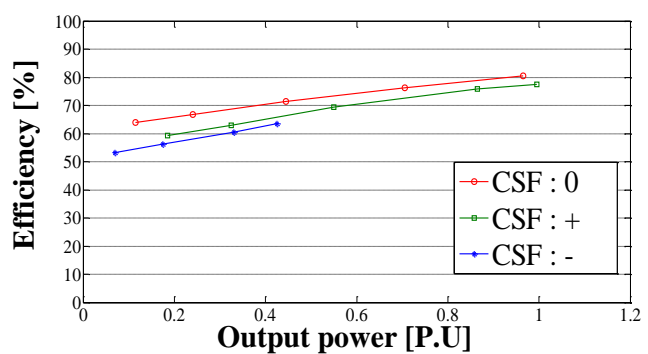

(b)

Fig. 10. Relationship between CSF and system efficiency (a) $1000 \mathrm{rpm}$ (b) $1500 \mathrm{rpm}$

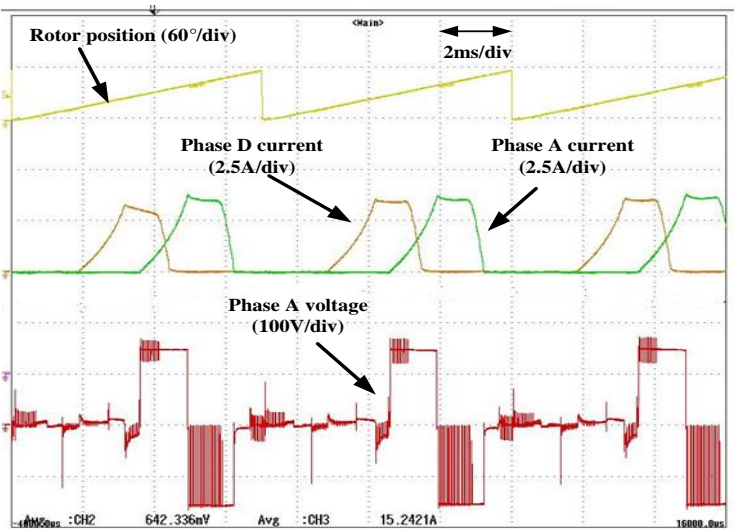

(a)

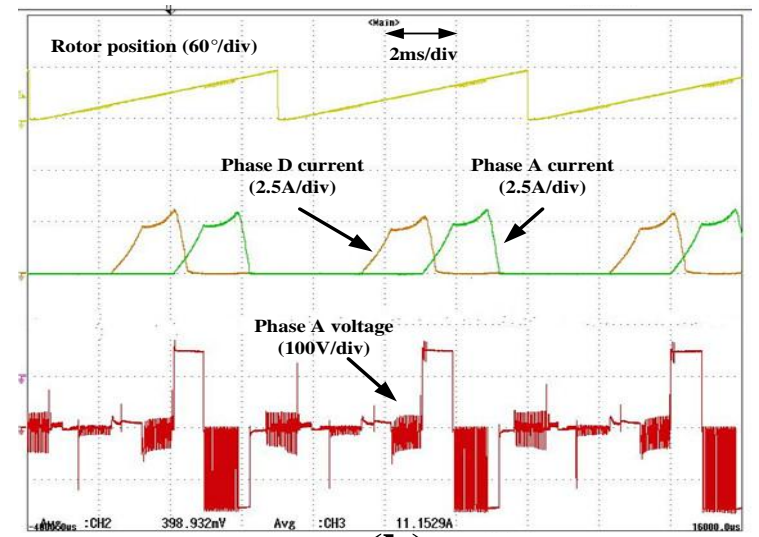

(b)

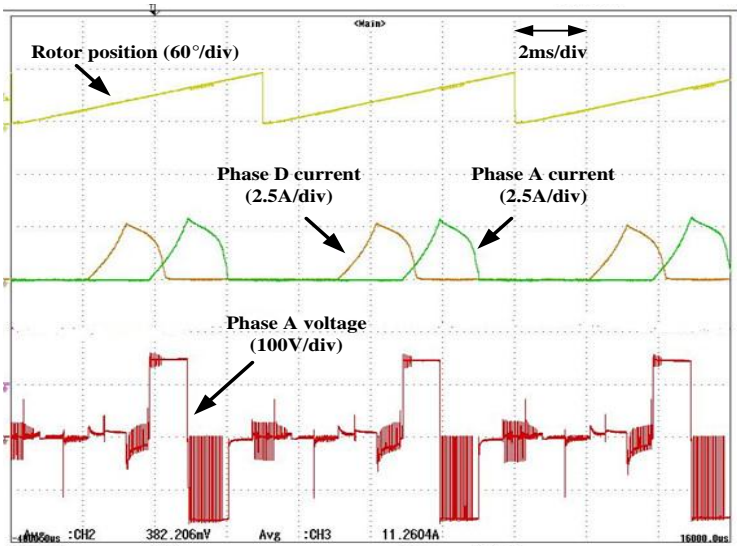

(c)

Fig. 11. Experimental waveforms at $1500 \mathrm{rpm}$ (a) CSF is "0" (b) CSF is "+" (c) CSF is "-_"

Fig. 11 gives the rotor position, phase current, and phase voltage of the three kinds of current shape at 1500rpm.

\section{Conclusion}

In this paper, the effect of current shape on the system efficiency is investigated when the SRG is operated under rated speed. The current slope factor CSF is proposed to express the current shape. The effect of current shape on the 
main electrical loss is analyzed in detail. A MAPC method which can be used over a wide speed range is presented. Using the method the optimal current shape can be obtained. The experimental system is set up. According to the simulation and experimental results, when CSF is " 0 ", the system efficiency is maximum at the same output power condition. In other words, the flat-top current shape is better for SRG when it is operated under rated speed. The control method proposed in this paper is simple, reliable and easy to achieve.

\section{Acknowledgements}

This work was supported by the Kyungsung University Research Grant in 2013

\section{References}

[1] D. A. Torrey, "Switched reluctance generators and their control," IEEE Transactions on Industrial Electronics, Vol. 49 No. 1, pp. 3-14, February 2002.

[2] Y. Sozer and D. A. Torrey, "Closed loop control of excitation parameters for high speed switched-reluctance generators," IEEE Transactions on Power Electronics, Vol. 19, No. 2, pp. 355-362, March 2004

[3] D. E. Cameron and J. H. Lang, "The control of high-speed variable-reluctance generators in electric power systems," IEEE Transactions on Industry Applications, Vol. 29, No. 6, pp. 1106-1109, November/December 1993.

[4] A. Radun, "Generating with the switched reluctance motor," in Proceedings of the 9th IEEE Applied Power Electronics Conference and Exposition (APEC'94), Vol. 1, pp. 41-47, February 1994.

[5] V. Nedic and T. A. Lipo, "Experimental verification of induced voltage self-excitation of a switched reluctance generator," in Proceedings of 35th IEEE Industry Applications Society Annual Meeting (IAS'00), Vol. 1, pp. 51-56, 2000.

[6] C. A. Ferreira, S. R. Jones, W.S. Heglund, and W. D. Jones, "Detailed design of a 30-kW switched reluctance starter/generator system for a gas turbine engine application," IEEE Transactions on Industry Applications, Vol. 31, No. 3, pp. 553-561, May/June 1995.

[7] R. Cardenas, W. F. Ray, and G. M. Asher, "Switched reluctance generators for wind energy applications," in Proceedings of IEEE Power Electronics Specialists Conference (PESC'95), Vol. 1, pp. 559-564, June 1995.

[8] B. Fahimi, A. R. B. Emadi, Jr. Sepe, "A switched reluctance machine-based starter/alternator for more electric cars," IEEE Transactions on Energy Conversion, Vol. 19, No. 1, pp. 116124, March 2004.

[9] E. Mese, Y. Sozer, J. M. Kokernak and D. A. Torrey, "Optimal excitation of a high speed switched reluctance generator," in Proceedings of the 15th IEEE Applied Power Electronics Conference and Exposition (APEC'00), Vol. 1, pp. 362-368, February 2000.

[10] B. Fahimi, S. Dixon, "Enhancement of output electric power in switched reluctance generators," in Proceedings of IEEE
Electric Machines and Drives Conference (IEMDC'03), Vol. 2, pp. 849-856, June 2003.

[11] Christos Mademlis and Iordanis Kioskeridis, "Optimizing performance in current-controlled switched reluctance generators," IEEE Transactions on Energy Conversion, Vol. 20, No. 3, pp. 556-565, September 2005.

[12] Iordanis Kioskeridis and Christos Mademlis, "Optimal efficiency control of switched reluctance generators," IEEE Transaction on Power Electronics, Vol. 21, No. 4, pp. 10621072, July 2006

[13] Zhenguo Li, Dongdong Gao, and Jin-Woo Ahn, "Power closed-loop control of switched reluctance generator for high efficiency operation," Journal of International Conference on Electrical Machines and Systems, Vol. 1, No. 3, pp. 128-133, September 2012.

[14] Jawad Faiz and Reza Fazai, "Optimal excitation angles of a high speed switched reluctance generator by efficiency maximization," in Proceedings of the 12th Power Electronics and Motion Control Conference (EPE-PEMC'06), pp. 287291, August/September 2006

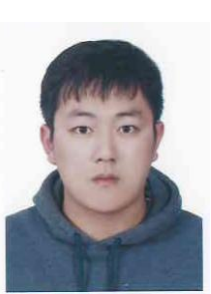

yang Yu was born in Liaoning, China in 1988. He received his B.S. degree in Electrical Engineering from Shenyang University of Technology, Shenyang, China, in 2011. Now he is a M.S. student of Shenyang University of Technology, Shenyang, China, and Kyungsung University, Busan, Korea. His research interests are motor design and motor control.

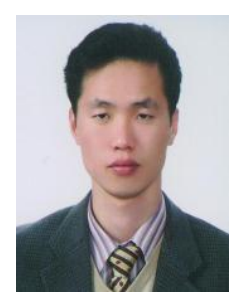

Dong-Hee Lee was born on Nov. 11, 1970 and received his B.S, M.S., and Ph. D degrees in Electrical Engineering from Pusan National University, Pusan, Korea in 1996, 1998, and 2001, respectively. He worked as a Senior Researcher of Servo R\&D Team at OTIS-LG, from 2002 to 2005. He has been with Kyungsung University, Pusan, Korea as an Assistant professor in the Department of Mechatronics Engineering since 2005. His major research field is Power Electronics and motor control system.

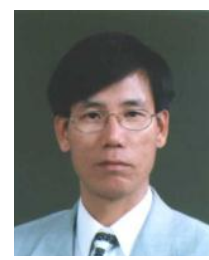

Jin-Woo Ahn was born in Busan, Korea, in 1958. He received his B.S., M.S., and Ph.D. degrees in Electrical Engineering from Pusan National University, Pusan, Korea, in 1984, 1986, and 1992, respectively. He has been with Kyungsung University, Busan, Korea, as a professor in the Department of Mechatronics Engineering since 1992. He was a visiting researcher in the Speed Lab at Glasgow University, U.K., a visiting professor in the Dept. of ECE and WEMPEC at the University of Wisconsin-Madison, USA, and a visiting 
professor in the Dept. of ECE at Virginia Tech from July 2006 to june 2007. He was the director of the Advance Electric Machinery and Power Electronics Center. He also has been the director of the Smart Mechatronics Advanced Research and Training Center from Aug. 2008 to July 2011 and has been the director of the Senior Easy Life Regional Innovation System since July 2008, President of Korea Regional Innovation System Association from December 2011 to December 2012 which are authorized by the Ministry of Knowledge Economy, Korea. He is the author of five books including SRM, the author of more than 150 papers and has more than 20 patents. His current research interests are advanced motor drive systems and electric vehicle drives. He has been the Editor-in-Chief of JICEMS. Dr. Ahn received several awards including the Best Paper Award from the Korean Institute of Electrical Engineers in 2002 and 2011, The Korean Federation of Science and Technology Society in 2003, Korean Institute of Power Electronics in 2007, Park Min-Ho Prize in 2009, Busan Science \& Technology Prize in 2011 and Ministerial Citation of Ministry of Knowledge Economy in 2011 and ministerial Citation of Ministry of Health and , respectively. He was geneal Chairman of ICEMS 2013 and is a geneal Chairman of IEEE/ICIT2014 He is a Fellow of the Korean Institute of Electrical Engineers, a member of the Korean Institute of Power Electronics and a senior member of the IEEE. 